EGU21-13351, updated on 29 Mar 2021

https://doi.org/10.5194/egusphere-egu21-13351

EGU General Assembly 2021

(c) Author(s) 2021. This work is distributed under

the Creative Commons Attribution 4.0 License.

\title{
Seismic hazard of the Western Makran subduction zone: Effect of heat flow on frictional properties combining mechanical and thermo-mechanical modelling approaches
}

\author{
sepideh pajang ${ }^{1,3}$, Nadaya Cubas ${ }^{1}$, Laetitia Le-pourhiet ${ }^{1}$, Eloise Bessiere ${ }^{1}$, Jean Letouzey ${ }^{1}$, \\ Seyedmohsen Seyedali ${ }^{2}$, Marc Fournier ${ }^{1}$, Philippe Agard ${ }^{1}$, Mohammad Mahdi Khatib ${ }^{3}$, \\ Mahmoudreza Heyhat ${ }^{3}$, and Mohammad Mokhtari ${ }^{4}$ \\ ${ }^{1}$ Institut des Sciences de la Terre Paris (ISTeP), sorbonne university, Paris, France (sepideh.pajang@sorbonne-universite.fr) \\ ${ }^{2}$ National Iranian Oil Company (NIOC), Tehran, Iran \\ ${ }^{3}$ Geoscience department, university of Birjand, Birjand, Iran \\ ${ }^{4}$ International Institute of Earthquake Engineering and Seismology (IIEES), Tehran, Iran
}

Western Makran is one of the few subduction zones left with a largely unconstrained seismogenic potential. According to the sparse GPS stations, the subduction is accumulating some strain to be released during future earthquakes. Mechanical modelling is first used to retrieve the spatial variations of the frictional properties of the megathrust, and discuss its seismogenic potential. To do so, we first build a structural map along the Iranian part of the Oman Sea and investigate three $\mathrm{N}$-S seismic profiles. The profiles are characterized by a long imbricated thrust zone that takes place at the front of the wedge. A diapiric zone of shallow origin lies in between the imbricated zone and the shore. Along the eastern and western shores, active listric normal faults root down to the megathrust. Eastern and western domains have developed similar deformation, with three zones of active faulting: the normal faults on shore, thrusts ahead of the mud diapirs, and the frontal thrusts. On the contrary, no normal faults are identified along the central domain, where a seamount is entering into subduction. From mechanical modelling, we show that along the eastern and western profiles, a transition from very low to extremely low friction is required to activate the large coastal normal fault. To propagate the deformation to the front, an increase of friction along the imbricated zone is necessary. These along-dip transitions could either be related to a transition from an aseismic to seismic behavior or the brittle-viscous transition.

To decipher, we run 2-D thermo-mechanical modelling incorporating temperature evolution, with a heat flow boundary condition. Our simulations are first calibrated to reproduce the heat flow estimates based on the BSR depth. Then the effects of the illite-smectite and brittle-viscous transitions on the deformation are investigated. The decrease in heat flow landward is due to the landward deepening of the oceanic plate and thickening of sediments of the accretionary wedge. Deformation starts at the rear of the model and migrates forming in-sequence, forward verging thrust sheets. The two brittle-viscous and illite-smectite transitions affect the topographic slope and friction. A reduction of friction due to the illite-smectite transition reduces the slope by normal faulting that does not appear in the brittle-viscous transition simulations. Therefore, the presence 
of normal faults could permit to distinguish viscously creeping segments from segments that deform seismically. As a consequence, the normal fault is most probably related to the presence of a seismic asperity, and the difference in deformation along strike would thus reveal the existence of two different patches, one along the eastern domain and a second along the western domain. Since no large earthquake has been historically reported and given the high convergence rate, a major earthquake will strike the Makran region. We suggest that the magnitude of this event will depend on the behavior of the Central region, and the ability of the earthquake to propagate from the eastern to the western asperity or the Pakistani Makran. 